\title{
PERCEPÇÃO DE PAIS ACERCA DO IMPACTO DE TECNOLOGIAS NO VIVER SAUDÁVEL DOS SEUS FILHOS*
}

\author{
Aline Medianeira Gomes Correa1 ${ }^{1}$ Adriana Dall'Asta Pereira², Dirce Stein Backes ${ }^{3}$, Carla Lizandra de Lima Ferreira², Eduarda
} Signor ${ }^{4}$, Marielle Kulakowski Obem ${ }^{5}$

${ }^{1}$ Enfermeira. Residente do Programa de Residência Em Enfermagem Obstétrica pelo Centro Universitário Franciscano. Santa Maria, RS, Brasil.

${ }^{2}$ Enfermeira. Doutora em Ciências. Docente do Departamento de Enfermagem do Centro Universitário Franciscano. Santa Maria, RS, Brasil.

${ }^{3}$ Enfermeira. Doutora em Enfermagem. Docente de Enfermagem do Centro Universitário Franciscano. Santa Maria, RS, Brasil. ${ }^{4}$ Enfermeira. Mestranda em Enfermagem. Universidade Federal de Santa Maria. Santa Maria, RS, Brasil.

${ }^{5}$ Discente de Enfermagem. Centro Universitário Franciscano. Santa Maria, RS, Brasil.

RESUMO: O objetivo do estudo foi identificar, mediante abordagem qualitativa de caráter descritivo, a percepção de pais acerca do impacto de tecnologias no viver saudável dos seus filhos. Os dados foram coletados em duas escolas, localizadas na cidade de Santa Maria, estado do Rio Grande do Sul, durante o segundo semestre do ano de 2013, por meio de quinze entrevistas semiestruturadas. Após a interpretação dos resultados, concluiu-se que o impacto das tecnologias na vida das crianças é evidente e negativo. Favorece o isolamento e o sedentarismo, além de interferir no desenvolvimento da criatividade das crianças, que deixam de buscar outras formas de brincar. Nesse contexto, cabe à enfermagem orientar os pais para que adquiram hábitos de vida saudáveis e, a partir de seu exemplo, consigam melhorar os costumes de seus filhos. Ressalta-se a importância do trabalho multidisciplinar, por parcerias que visem a estimular o cuidado com a saúde infantil.

DESCRITORES: Enfermagem; Criança; Tecnologia; Comportamentos saudáveis.

\section{PARENTS AWARENESS ABOUT TECHNOLOGY IMPACT ON THE HEALTHY LIVES OF THEIR CHILDREN}

\begin{abstract}
The goal of this study is to identify, through qualitative approach with descriptive content parentsawareness about technology impact on healthy lives of their children. Data was collected in two schools, located in the city of Santa Maria, state of Rio Grande do Sul, during the second semester in 2013, by doing fifteen semi-structured interviews. After analyzing the results, it was noticed that the impacttechnologies have on lives of children is clear and negative. It promotes isolation and sedentariness, besides, the interferance on the development of the child, that keeps from seeking other ways of amusement. In this context, the nursing department sees as its duty to guideparents to lead ahealhty lifestyle, and from then on, following as example to improve thehabits of their children. It must be observed the importance of multidisciplinary work, through partnerships that focus on estimulating the care about the health of the children.
\end{abstract}

DESCRIPTORS: Nursing; Child; Technology; Healthy habits.

\section{PERCEPCIÓN DE PADRES ACERCA DEL IMPACTO DE TECNOLOGÍAS EN EL VIVIR SALUDABLE DE SUS HIJOS}

RESUMEN: El objetivo del estudio fue identificar, por medio de abordaje cualitativo de carácter descriptivo, la percepción de padres acerca del impacto de tecnologías en el vivir saludable de sus hijos. Los datos fueron obtenidos en dos escuelas, ubicadas en la ciudad de Santa Maria, estado de Rio Grande do Sul, durante el segundo semestre del año de 2013, por medio de quince entrevistas semiestructuradas. Tras la interpretación de los resultados, se concluye que el impacto de las tecnologías en la vida de los niños es evidente y negativo. Favorece el aislamiento y el sedentarismo, además de interferir en el desarrollo de I creatividad de los niños, que dejan de buscar otras formas de jugar. En ese contexto, es responsabilidad de la enfermería orientar los padres para que adquieran hábitos de vida saludables y, con su ejemplo, logren mejorar las costumbres de sus hijos. Se destaca la importancia del trabajo multidisciplinar de asociaciones para estimular el cuidado con la salud infantil.

DESCRIPTORES: Enfermería; Niño; Tecnología; Comportamientos saludables.

*Artigo extraído de Trabalho Final de Graduação, intitulado: “A percepção dos pais acerca do impacto das tecnologias no viver saudável dos seus filhos". Centro Universitário Franciscano, 2013.

Autor Correspondente:

Eduarda Signor

Universidade Federal de Santa Maria

R. Floriano Peixoto, 1139, ap 93 - 97015-371 - Santa Maria, RS, Brasil

E-mail: eduardasignor@hotmail.com
Recebido: 29/04/2015 Finalizado: 05/10/2015 


\section{INTRODUÇÃO}

A contemporaneidade está marcada por muitos avanços, e é inegável a influência das transformações tecnológicas e científicas sobre os vários campos da atividade humana. Todos os sistemas, seja o social, o econômico, o político ou o cultural, lidam com desafios decorrentes das mudanças tecnológicas ${ }^{(1)}$.

O termo "tecnologia" refere-se a todas as invenções humanas que estendem a sua capacidade física, sensorial, motora ou mental, facilitam e simplificam o seu trabalho, enriquecem suas relações interpessoais ou simplesmente Ihes proporcionam prazer $^{(2)}$. São tecnologias comumente usadas pelo homem o celular, o computador, o videogame, o tablet, a televisão, dentre outros instrumentos tecnológicos disseminados em nossa cultura. Dessa forma a tecnologia, criada para interagir com o homem, pode ser empregada para controlar, transformar ou criar coisas e processos naturais ou sociais; conforme a maneira como é usada, torna-se capaz de determinar o estilo de vida de toda uma sociedade, exercendo um controle cultural e social sobre o ser humano(3).

Portanto, os instrumentos tecnológicos estão atrelados ao cotidiano social, podendo moldar comportamentos, posicionamentos e influenciar na mudança de valores e de costumes, pois contribuem para a disseminação de informações e tornam-se parte dos pensamentos e das discussões entre os indivíduos. Ao se ampliar a reflexão sobre a utilização das tecnologias, percebe-se como elas contribuem para a formação de conduta e de opinião, colaborando para a transmissão do saber popular e para a disseminação de hábitos de vida.

Assim, pensa-se que os profissionais da saúde devem atentar para a modelação que as tecnologias realizam sobre os sujeitos, uma vez que essas influenciam sua cultura e seus hábitos de vida. Neste estudo, há uma preocupação potencial com as crianças, pois elas estão em processo de construção ética e moral, e são envolvidas invariavelmente pelos excessos de informações e pela atual cultura tecnológica, recebendo graves influências em seu viver saudável.

Sabe-se que a infância é uma fase do ciclo vital em que o ser humano passa por vários processos de aprendizagem, bem como por novas e contínuas adaptações ${ }^{(4)}$. Nesse estágio da vida há grande interação e captação de estímulos, e é ativamente nessas relações, principalmente com os instrumentos tecnológicos, que a saúde infantil está em constante influência.

A criança é um ser biológico e simbólico em construção e adaptação ao meio em que está inserida. As condições ambientais do micro e do macrossistema em que vive e a sua estrutura familiar são aspectos significativos no desenvolvimento de suas potencialidades e de seu modo de ser e de conhecer o mundo, modelando seus hábitos de vida e, obviamente, o seu viver saudável ${ }^{(5)}$.

O desenvolvimento da ciência infantil é resultadodeprocessosinterativos, noqualacriança constrói suas noções a partir das resistências que o meio lhe oferece. Dessa forma, o saber infantil resulta das interações com os outros e com os objetos, nesse caso, as tecnologias ${ }^{(6)}$. Corrobora Piaget $^{(7: 14)}$, dizendo que "o conhecimento não parte nem do sujeito nem do objeto, mas da relação indissociável entre eles, para avançar daí na dupla direção de uma exteriorização objetivante e de uma interiorização reflexiva". $\mathrm{Na}$ relação com a tecnologia, o conhecimento infantil está em constante desenvolvimento, porém, esse conhecimento não é sinônimo de ciência, mas fruto de diversas formas e modos de produção dos saberes, entre muitos modos de conhecer ${ }^{(8)}$.

Embora o acesso às informações e a presença de tecnologias na sociedade sejam de grande valia, esses não garantem o crescimento intelectual e a promoção do viver saudável. Por isso deve existir um cuidado com quais elementos tecnológicos o público infantil utiliza e de que maneira o faz.

Portanto, sabe-se que as tecnologias e informações vinculadas a elas possuem grande poder sobre a cultura atual. Contudo, cabe a reflexão sobre que acréscimo a tecnologia tem dado aos hábitos e costumes, pontualmente às questões de saúde, ao desenvolvimento da criança e à sua formação como indivíduo adulto.

A partir dessas reflexões faz-se o seguinte questionamento, relativo ao objetivo geral deste estudo: Qual a percepção dos pais acerca do impacto das tecnologias no viver saudável dos seus filhos? São, por sua vez, os objetivos específicos: conhecer a conduta dos pais em relação ao uso das tecnologias pelas crianças; descrever as relações estabelecidas entre pais e filhos com a utilização das tecnologias; identificar a influência das tecnologias no viver saudável das crianças. 


\section{METODOLOGIA}

O método utilizado para atingir os objetivos deste estudo foi a abordagem qualitativa com caráter descritivo. Esse tipo de metodologia de pesquisa proporciona ao pesquisador a possibilidade de tentar compreender a maneira como os sujeitos pensam e reagem diante das questões focalizadas, além de auxiliar na compreensão de sentimentos, valores, atitudes e temores das pessoas, explicando suas ações diante de um problema ou situação( ${ }^{(9)}$.

A pesquisa foi desenvolvida nos meses de setembro e outubro do ano de 2013. Foram realizadas quinze entrevistas, com pais de crianças entre seis e doze anos de idade, selecionados de acordo com alguns critérios previamente determinados, em duas escolas do município de Santa Maria, estado do Rio Grande do Sul. Para definirem-se as escolas, fez-se um sorteio entre públicas e particulares, a fim de contrapor possíveis diferenças e enriquecer a pesquisa. Deve-se salientar que os responsáveis pelas instituições de ensino autorizaram previamente a pesquisa e disponibilizaram uma sala de aula para a realização das entrevistas, com o intuito de evitar possíveis transtornos e/ou a exposição dos participantes. O convite aos pais deu-se no horário de entrada ou de saída de seus filhos na escola.

Os critérios para poderem participar da entrevista foram, de acordo com os objetivos do estudo, que os participantes fossem pais de crianças que tivessem contato com algum tipo de tecnologia (como o computador, o celular, a televisão e/ou o vídeo game, entre outros instrumentos tecnológicos), e que residissem com seus filhos, pois o convívio é essencial para acompanhar melhor os seus hábitos. Foram excluídos pais que não residissem com seus filhos e pais de filhos únicos. A escolha da faixa etária entre seis e doze anos justifica-se por ser esse o período em que as crianças desenvolvem seus próprios valores morais, seus sentimentos, o respeito mútuo, a honestidade, o companheirismo e a noção de justiça ${ }^{(10)}$.

Os sujeitos que aceitaram participar do estudo foram informados sobre os seus objetivos e assinaram o Termo de Consentimento Livre e Esclarecido (TCLE), tendo liberdade para deixarem de participar da entrevista em qualquer momento, caso desejassem. Para que os dados fossem melhor captados, os participantes consentiram a gravação das entrevistas. Como forma de assegurar-Ihes o total anonimato, a autora do estudo assinou um termo de confidencialidade.

O local de realização das entrevistas foi prédeterminado com os participantes, as quais foram semiestruturadas, favorecendo a contextualização de experiências, vivências e sentidos, e contribuindo para esclarecer a problemática da investigação ${ }^{(11)}$.

Antes de iniciar a entrevista, que seguiu um roteiro com pontos direcionados aos objetivos do estudo, a pesquisadora elucidou o que são tecnologias. As questões norteadoras foram: $\mathrm{O}$ que é viver saudável para você? Qual o impacto das tecnologias no viver saudável dos seus filhos? Qual a sua conduta frente ao uso das tecnologias por seus filhos?

Os dados foram analisados com base na teoria de Bardin. Optou-se pela Análise do Conteúdo ${ }^{(12)}$, que é um método empírico cuja função primordial é o desvendar crítico. Esse tipo de apreciação dos dados objetiva a descoberta das relações existentes entre o conteúdo do discurso e os aspectos exteriores, o que permite a compreensão, a utilização e a aplicação de um determinado conteúdo ${ }^{(13)}$. Nesse sentido, foram aplicadas ao material técnicas organizadas em três fases: préanálise, exploração do material e tratamento dos resultados, inferência e interpretação.

Foram observados todos os preceitos éticos preconizados pela resolução 466/12(14). A pesquisa foi aprovada pelo Comitê de Ética e Pesquisa do Centro Universitário Franciscano sob o $\mathrm{n}^{\circ} \mathrm{da}$ CAAE: 19403313.3.0000.5306 e registro na Comissão Nacional de Ética em Pesquisa - CONEP sob o $\mathrm{n}^{\circ}$ 365.832.

\section{RESULTADOS}

No intuito de facilitar a interpretação dos resultados, núcleos temáticos como o viver saudável, o impacto no convívio social, o sedentarismo e a tecnologia, a intervenção dos pais, entre outros, foram agrupadas as seguintes categorias empíricas: "percebendo o viver saudável das crianças nas relações e atividades cotidianas" e "compreendendo o impacto das tecnologias no cotidiano e saúde dos filhos".

Foram identificadas pelos pais dificuldades nas relações estabelecidas com as crianças pelo uso das tecnologias, dispondo de rotinas para mediálas no viver saudável de seus filhos.

Percebendo o viver saudável das crianças nas relações e atividades cotidianas 
Os recortes de depoimentos transcritos abaixo evidenciam que, para a maioria dos pais, o viver saudável da criança está atrelado principalmente às suas atividades cotidianas, à prática de exercícios, como as brincadeiras, por exemplo, em que ela costuma movimentar-se bastante, e à alimentação adequada. Entretanto, alguns pais ressaltaram a importância das relações de seus filhos, isto é, de seu convívio com os amigos e a família.

Viver saudavelmente é ter lazer, poder praticar algum esporte, ter a fase de criança, jogar com os amigos, conviver com eles e ter uma alimentação saudável. [P1]

Ah! Para mim, criança saudável é basicamente aquela que come bem, brinca bem, está em um ambiente bom. Viver saudavelmente significa ganhar amor da família. [P3]

É poder ter uma alimentação balanceada, realizar atividades físicas variadas. [P4]

A criança saudável é a que estuda e brinca, mas o brinquedo não pode ser a internet ou a televisão, brincar é correr também, ter o contato com a natureza, estar na pracinha com outras crianças. [P8]

Para mim seria uma criança que tivesse o direito de brincar, saudável que não tenha nenhuma patologia, sem nenhuma doença em si. Então que tenha uma mente saudável. [P15]

Eles perpassam o aspecto da doença quando falam sobre o tipo de ambiente em que a criança precisa estar inserida para crescer saudavelmente, o qual deve proporcionar saúde, afeto e o desenvolvimento de estado de espírito pleno.

Além disso, os pais acreditam que a saúde das crianças está sob a responsabilidade deles e da escola. Nos depoimentos transcritos abaixo, percebe-se a preocupação em conduzir da melhor maneira possível o viver saudável dos filhos.

Acho que a criança é saudável quando a mãe e a escola conseguem proporcionar uma vida saudável a ela, além de uma boa alimentação e uma boa educação. Então, a responsabilidade é dos dois. [P1]

Hoje está difícil controlar a saúde da criança, se não dermos o exemplo fica mais difícil ainda. A criança é espelho dos pais; se mesmo a gente comendo verdura, por exemplo, já é difícil, imagina se a gente não faz como deve ser. Eles sabem tudo, nos cobram quando não fazemos algo que cobramos deles. [P9]

A escola faz a parte dela, os professores oferecem a educação física, dão sugestões de lanche, reforçam com os pais o que não deve ser dado para as crianças, mas elas pedem besteira, a gente tenta não dar, às vezes, mas na correria é mais fácil aquele lanche pronto. [P11]

Alguns afirmaram que a falta de tempo e a correria do dia-a-dia são dificuldades enfrentadas na criação dos filhos, pois lhes impedem de desempenhar melhor as obrigações básicas de progenitores, como cuidar a alimentação das crianças, por exemplo.

Eu ando preocupada, porque ele está com o 'sangue alterado'; levei ao pediatra e agora à nutricionista para saber o que tem de errado com a saúde dele. Estamos tendo que tomar medidas drásticas que envolvem toda a família, porque é culpa nossa, porque a gente come mal e, consequentemente ele também. [P13]

As crianças assistem à televisão e por meio do exemplo dos pais, já são consumidoras dos produtos, como expressa a fala a seguir:

Estamos tentando cortar um pouco a televisão, porque ele come muita bobagem e nem vê. Sem mencionar que pede para comprarmos tudo o que ele vê na TV. Tentamos conversar, explicar que nem sempre dá, mas fica bem difícil. [P13]

\section{Compreendendo o impacto das tecnologias no cotidiano e saúde dos filhos}

Como corroboram as respostas transcritas abaixo, todos os sujeitos entrevistados afirmaram que as tecnologias causam impacto negativo na vida de seus filhos. Contudo, a grande preocupação dos pais está no isolamento da criança e no sedentarismo:

Tem um impacto muito grande, porque eu acho que a criança perde muito a convivência, tanto com os amigos quanto com a família, porque fica muito concentrada no computador, em jogos eletrônicos e na televisão, então essa parte da convivência fica muito a desejar. [P2]

Prejudica sim, meu filho só quer saber do videogame, se eu deixo fica horas a fio, isso é prejudicial, ele mal come, mal fala com a gente, com a família. [P14]

Quando tiramos do quarto, do mundinho dos desenhos, no convívio com as pessoas ele é quieto. [P13]

Bom, o impacto é tanto que às vezes não querem sair de casa para ficarem olhando TV. [P10]

Além das questões relacionais, que influenciam na construção da criança como indivíduo, as 
tecnologias têm preocupado os pais no que diz respeito ao seu impacto na saúde dos filhos, o que pode ser constatado nos depoimentos abaixo:

Impressiono-me com o sedentarismo deles, esses tempos levamos ao campo para correr, logo ficaram sem fôlego, cansados, também, mal saem no pátio de casa, então eu acho que tem impacto sim. [P7]

Acho que é um efeito intenso na atividade física. [P5]

O impacto é total, porque se torna sedentário, não pratica nenhuma atividade, nem quando tentamos levá-lo a fazer. [P13]

A partir das falas, torna-se evidente que as tecnologias podem proporcionar um efeito negativo no viver saudável das crianças, uma vez que as induzem ao sedentarismo.

Na opinião dos pais, o brincar é essencial, mas para que ocorra são necessárias várias intervenções e estímulos, como pode ser visto nas falas a seguir:

Acho que brincar é tudo para a criança, é essencial para elas. [P2]

Se outras crianças chegam, eles mal brincam com elas, só ficam 'enfurnados' no quarto com videogame, tenho que forçá-los a sair para brincarem lá fora, correrem um pouco. [P4]

Lá em casa é uma briga para sair do computador e da frente da televisão, parece que não existem outras brincadeiras, que não sabem brincar de outra coisa, é terrível mesmo. [P16]

A partir da fala dos participantes, é perceptível como as tecnologias interferem em diversos aspectos da vida das crianças, que muitas vezes deixam de brincarem ao ar livre paraficarem dentro de casa, navegando na internet, por exemplo. O excesso de elementos tecnológicos no cotidiano infantil afeta a convivência social e a saúde das crianças, pois elas não se alimentam corretamente quando estão frente à televisão ou ao computador. Além disso, por influência principalmente da mídia televisiva, acabam consumindo em demasia alimentos industrializados, que não fazem bem ao organismo. Tudo isso é agravado pelo dia-a-dia atarefado dos pais, que não conseguem controlar a alimentação dos filhos. Nesse ponto entra o papel da escola e dos professores, que tentam reeducar as crianças no que diz respeito aos cuidados com a saúde, oferecendo-lhes momentos de recreação e de atividades físicas, mostrando-Ihes também o quão importante é, para a mente e para o corpo, manter uma alimentação saudável e balanceada.

\section{DISCUSSÃO}

Durante o desenvolvimento neuropsicomotor da criança, as figuras materna e paterna são tidas como referenciais a serem seguidos e imitados ${ }^{(15)}$. Os pais e/ou os cuidadores são os responsáveis pela estrutura emocional dos seus filhos e desempenham o papel de facilitadores no seu processo de crescimento e desenvolvimento(5). Tanto os pais quanto a escola devem conduzir a criança a hábitos saudáveis e procurar mediante a qualidade de vida promover sua saúde.

Hábitos inadequados, muitas vezes espelhados pelosadultos, fazemcomqueaumentegravemente o número de crianças e adolescentes com doenças crônico-degenerativas. Dislipidemia, hipertensão, diabetes mellitus do tipo II são problemas que os pediatras estão tratando com frequência ascendente ${ }^{(16)}$.

Alterações nutricionais resultam de uma série de fatores, mas estão principalmente atreladas à ingestão excessiva de alimentos industrializados comprados pelos pais. Esse consumo é acentuado pelo estímulo causado pelo marketing das mídias publicitárias, que focam cada vez mais o público infantil, já que esse não possui o discernimento necessário para optar pelo produto mais saudável. $\mathrm{Na}$ televisão, em geral, as imagens são veiculadas rapidamente e a criança não tem tempo suficiente para compreender parte do que é transmitido, nem para desenvolver um senso crítico ou raciocínio lógico a respeito de tais informações ${ }^{(17)}$.

Para o mercado, antes de tudo, a criança é um consumidor em formação e uma poderosa influência nos processos de escolha de produtos ou serviços. Segundo o Projeto Criança e Consumo, do Instituto Alana, sete em cada dez pais entrevistados afirmam ser influenciados pelos filhos na hora da compra. De acordo com o seminário Infância e Comunicação: Marcos Legais e Políticas Públicas, atualmente as crianças chegam a participar de $80 \%$ das decisões de compra em uma família ${ }^{(18)}$.

As práticas de consumo desenfreado, associadas às propagandas entre as crianças e os adolescentes, estão relacionadas ao surgimento de inúmeros problemas, como a erotização precoce, os transtornos de comportamento e os alimentares, a violência, e o estresse familiar ${ }^{(19)}$.

Assim, o atual estilo de vida infantil possui forte relação com as condições ambientais, com os hábitos gerais de sua estrutura familiar, também com o uso de tecnologias e a forte 
influência da mídia associada ao capitalismo. Os pais expressam dificuldades e preocupações com relação a alguns hábitos de seus filhos e revelam saber que são um dos maiores responsáveis na condução do viver saudável dessas crianças.

Contudo, as crianças estão em processo de transformação, portanto é possível proporcionarlhes um viver saudável, pois, se comparadas aos adultos, possuem maior flexibilidade para a mudança de seus hábitos de vida, devido ao fato de não estarem ainda tão arraigadas ao cotidiano. Entretanto, para essa conquista, seriam necessárias estratégias de educação que envolvam pais, familiares, cuidadores, educadores e profissionais de saúde ${ }^{(20)}$.

Para a nova geração, inserida no mundo digital, estão surgindo novos riscos à saúde decorrentes do uso indevido das tecnologias. $\mathrm{O}$ excesso de tempo em frente ao computador, por exemplo, causa insuficiência nas horas de sono e predispõe as crianças aos hábitos sedentários, além de causar a queda do rendimento escolar, entre outros ${ }^{(21)}$. Progressivamente, as crianças têm se dedicado cada vez mais ao divertimento passivo e solitário, frente à $\mathrm{TV}$, ao videogame e ao computador que, mal direcionados, induzem à falta de criatividade, ao desinteresse pela leitura, à redução da curiosidade, ao sedentarismo e ao isolamento ${ }^{(22)}$.

Os relatos dos participantes da pesquisa demonstram uma realidade preocupante, pois as crianças estão deixando de relacionar-se com o contexto familiar para ficarem focadas apenas no mundo virtual das mídias eletrônicas. Sem dosagem e controle, o mundo virtual vai, progressivamente, confundindo os seus limites com o mundo real. Os equipamentos de tecnologia da informação vão transformando os comportamentos e as formas de se relacionar com a família, com os amigos e com as novas possibilidades de viajar pelo mundo sem sair de casa $^{(23)}$.

É inquestionável a importância da interação da criança com o mundo digital, principalmente no seu processo de desenvolvimento, essa experiência é vista como parte necessária da socialização na infância, providenciando um espaço de aprendizagem de papéis, desenvolvimento cognitivo e moral, domínio de impulsos agressivos e aquisição de competências sociais globais ${ }^{(24)}$.

Porém, as tecnologias podem causar isolamento social da criança, tornando-as menos altruístas, ou seja, menos preocupadas em ajudar ou oferecer coisas boas ao próximo, pois ficam conectadas por horas, abandonando os interesses de terceiros ${ }^{(25,26)}$. Elas também estão deixando de desenvolver a empatia e tornam-se menos dispostas à construção de amizades e de confiança ${ }^{(26)}$.

A tecnologia pode impedirque o público infantil desenvolva relacionamentos fundamentais na fase inicial da vida. Tem havido um aumento no narcisismo e um declínio na empatia entre os jovens. Embora não se possa atribuir uma relação direta com a tecnologia, é nítido que o surgimento de novas mídias e o maior alcance junto à cultura popular trouxe prejuízos. Uma criança que não desenvolve a relação interpessoal pode se tornar um indivíduo inseguro e despreparado para enfrentar pressões, provocações e situações $\operatorname{adversas}^{(27)}$.

O sedentarismovem acometendo cada vez mais a população infanto-juvenil e é um dos principais fatores de risco para a obesidade. Considera-se que o sedentarismo na infância e na adolescência tende a se tornar cada vez mais comum por conta do novo modelo de vida adotado pelas crianças e por seus familiares cuidadores ${ }^{(28)}$.

A brincadeira pode ser uma maneira de estimular a criança a movimentar-se, pois brincar é mais do que exercer uma atividade física; brincando ela não apenas se diverte, mas também aprende, cria, recria e se relaciona com o mundo ${ }^{(15)}$.

As falas dos pais demonstram que, em sua percepção, existem várias formas de brincar e que as brincadeiras tecnológicas têm ocupado muito espaço no cotidiano das crianças, apesar de não ser as mais adequadas para elas. Essa presença contínua, juntamente à falta de rotatividade de atividades, faz com que os pais tenham que intervir na rotina dos filhos, afastando-os desse hábito prejudicial e atraindo-os para o que, em sua concepção, significa brincar efetivamente.

\section{CONSIDERAÇÕES FINAIS}

Constatou-se que, na visão dos pais, a saúde infantil encontra-se sob responsabilidade deles e da escola, e está diretamente relacionada com as atividades físicas, a alimentação e as relações familiares. Todos demonstraram preocupação com a influência de seus hábitos na saúde das crianças, os quais estão associados à indução do consumo, por parte da mídia. 
O impacto do uso das tecnologias no viver saudável das crianças é evidente e inegável, uma vez que, segundo os pais, as tecnologias proporcionam o isolamento, o sedentarismo e a falta de outras formas de brincar. Apesar disso, quando questionados sobre a relação dos seus filhos com as tecnologias, a maioria dos pais focou-se sobre a frequência com que aqueles as utilizam, poucos refletiram sobre essa relação. A falta de reflexão vai ao encontro da presença da televisão em grande parte da vida das crianças, já que os pais, por vezes, a utilizam como babáeletrônica, corroborando para a formação de conceitos, atitudes e valores trazidos pela tela e que deveriam ser transmitidos pela família.

Diante dos resultados e da importância do trabalho multidisciplinar destaca-se a enfermagem, por sua formação generalista e atuação como educadora em saúde. O profissional de enfermagem pode ser o orientador dos pais na adequação dos seus hábitos de vida e dos de seus filhos, na busca pelo viver saudável, com relevância nas singularidades e pluralidades. $\mathrm{O}$ enfermeiro deve alertá-los sobre o mau uso das tecnologias pelas crianças e conduzir os pais ao acompanhamento e controle efetivo, uma vez que quando utilizadas didaticamente tornam-se potentes ferramentas para o desenvolvimento infantil.

\section{REFERÊNCIAS}

1. Domingues D. A Humanização das Tecnologias pela Arte. In: Domingues D. A Arte no Século XXI: a humanização das tecnologias. São Paulo: UNESP; 1997. p. 17.

2. Chaves EOC. Tecnologia na educação, ensino a distância, e aprendizagem mediada pela tecnologia: conceituação básica. Rev. Educ. PUC-Camp. [Internet] 1999; 3(7) [acesso em 15 set 2012]. Disponível: http:// periodicos.puc-campinas.edu.br/seer/index.php/ reveducacao/article/download/421/401.

3. Silva RC, Ferreira MA. A tecnologia em saúde: uma perspectiva psicossociológica. Esc. Anna Nery. [Internet] 2009;13(1) [acesso em 10 set 2012]. Disponível: http://www.scielo.br/pdf/ean/v13n1/v13n1a23.pdf.

4. Freitas HMB, Backes DS, Pereira ADA, Ferreira CLL, Marchiori MRC, Souza MHT, et al. Significados que os profissionais de enfermagem atribuem ao cuidado de crianças institucionalizadas com AIDS. Texto Contexto Enferm. [Internet] 2010; 19(3) [acesso em 12 set 2012]. Disponível: http://dx.doi.org/10.1590/S010407072010000300013.

5. Schaurich D, Medeiros HMF, Motta MGC.
Vulnerabilidades no viver de crianças com AIDS. Rev. Enferm. UERJ. [Internet] 2007; 15(2) [acesso em 28 set 2012]. Disponível: http://www.facenf.uerj.br/v15n2/ v15n2a20.pdf.

6. Stoltz T. Mídia, cognição e educação. Educar, Curitiba. [Internet] 2005; (26) [acesso em 6 set 2012]. Disponível: http://www.scielo.br/pdf/er/n26/n26a11. pdf.

7. Piaget J, Gréco P. Aprendizagem e conhecimento. Rio de Janeiro: Livraria Freitas Bastos; 1959/1974.

8. Costa B. Pertinência, atualidade e importância política das referências da Educação Popular do surgimento aos desafios atuais (2000) In: Marteleto RM, Ribeiro LB, Guimarães, C. Informação em movimento: produção e organização do conhecimento nos espaços sociais. Civitas - Revista de Ciências Sociais, ano 02, nº 1; 2002. p. 72.

9. Merigui MB, Praça NS. Abordagens teóricometodológicas qualitativas. Rio de Janeiro: Guanabara Koogan; 2003.

10. Bock AMB. Psicologias: Uma Introdução ao Estudo de Psicologia. Barra Funda: Saraiva; 2002.

11. Minayo MCS. O desafio do conhecimento: pesquisa qualitativa em saúde. $12^{\mathrm{a}}$ ed. São Paulo: HucitecAbrasco; 2010.

12. Bardin L. Análise de conteúdo. São Paulo: Edições 70; 2011.

13. Santos AAG, Silva RM, Machado MFAS, Vieira LJES, Catrib AMF, Jorge HMF. Sentidos atribuídos por profissionais à promoção da saúde do adolescente. Ciênc. saúde coletiva. [Internet] 2012; 17(5) [acesso em 5 out 2012]. Disponível: http://dx.doi.org/10.1590/ S1413-81232012000500021.

14. Ministério da Saúde (BR). Conselho Nacional de Saúde. Diretrizes e normas regulamentadoras de pesquisa envolvendo seres humanos. Resolução $n$. 466, de 12 de dezembro de 2012. [Internet] Brasília; 2012 [acesso em 02 out 2013]. Disponível: http:// conselho.saude.gov.br/resolucoes/2012/Reso466.pdf.

15. Pontes TE, Costa TF, Marum ABRF, Brasil ALD, Taddei JAAC. Orientação nutricional de crianças e adolescentes e os novos padrões de consumo: propagandas, embalagens e rótulos. Rev. paul. pediatr. [Internet] 2009; 27(1) [acesso em 10 out 2012]. Disponível: http://dx.doi.org/10.1590/S010305822009000100015.

16. Salgado J. Atual estilo de vida reflete-se na pediatria. [Internet] 2008 [acesso em 7 set 2012]. Disponível: http://www2.uol.com.br/vyaestelar/dieta_criancas. htm. 
17. Pontes TE, Costa TF, Ferreira AB, Taddei JA, Lopes LA, Brasil AL. Análise da adequação nutricional e sócioeconômica de alimentos veiculados em propagandas durante o horário infantil nas duas emissoras de maior audiência da TV brasileira [iniciação científica]. São Paulo (SP): Unifesp; 2007.

18. Sarres C. Crianças participam de $80 \%$ das decisões de compra da família, aponta instituto. [Internet] 2013 [acesso em 7 nov 2012]. Disponível: http://agenciabrasil. ebc.com.br/noticia/2013-03-05/criancas-participamde-80-das-decisoes-de-compra-da-familia-apontainstituto.

19. Schmitt M. A fantástica fábrica de propagandas: uma abordagem educativa e a sua recepção junto ao público infantil [monografia]. Blumenau (SC): Universidade Regional de Blumenau; [Internet] 2010 [acesso em 4 out 2012]. Disponível: http://www.bc.furb. br/docs/MO/2011/346023_1_1.pdf.

20. Alana. Instituto Alana. Por que a publicidade faz mal para as crianças. Projeto Criança e Consumo. [Internet] $2^{a}$ ed. São Paulo: Instituto Alana; 2009. [acesso em 7 nov 2012]. Disponível: http://pt.scribd.com/doc/62689390/ Por-Que-a-Publicidade-Faz-Mal-Para-as-Criancas.

21. Pinheiro ARO, Ministério da Saúde (BR), Secretaria de Atenção à Saúde, Departamento de Atenção Básica, Coordenação-Geral da Política de Alimentação e Nutrição. A Promoção da alimentação saudável como instrumento de prevenção e combate ao sobrepeso e obesidade. [Internet] 2004 [acesso em 16 out 2012]. Disponível: http://189.28.128.100/nutricao/docs/geral/ obesidade2004.pdf.

22. Bergamo G. Um novo bicho-papão. São Paulo: Veja; 2005; 38(33):110-1.

23. Silva Junior ASAH, Rosas Junior JR. Violência Sexual Contra Crianças e Adolescentes: Conceitos-chave. Revista do Laboratório de Estudos da Violência da UNESP - Marília; Ed 14, 2014. p. 156.

24. Carvalho RGG. Isolamento social nas crianças propostas de intervenção cognitivo-comportamental. Rev Iberoamericana de Educación, 2006; 40(3): p. 01 In: Kendal P, Morison, P. Integrating Cognitive and behavioural procedures for the treatment of socially isolated children. cognitive behavior therapy with children. New York: Plenum Press; 1983. p. 261-288.

25. Paiva $N M N$, Costa JS. A influência da tecnologia na infância: desenvolvimento ou ameaça? O Portal dos Psic. [Internet] 2015 [acesso em 23 ago 2015]. Disponível: http://www.psicologia.pt/artigos/textos/ A0839.pdf.

26. Garcia J. Tablets e smartphones podem trazer prejuízos às crianças se usados sem moderação. Diário de Sta Maria. Rio Grande do Sul; 2015 [acesso em 29 set 2015]. Disponível: http://diariodesantamaria. clicrbs.com.br/rs/bem-viver/noticia/2015/06/tablets-esmartphones-podem-trazer-prejuizos-as-criancas-seusados-sem-moderacao-4775855.html

27. Carvalho RGG. Isolamento social nas crianças: propostas de intervenção cognitivo-comportamental. Rev. Iberoamericana de Educación. 2006; (40/3):1-12.

28.Taylor J.Aremediacreatingageneration of narcissists? [Internet] 2012 [acesso em 5 nov 2012]. Disponível: http://blog.seattlepi.com/jimtaylor/2012/10/23/aremedia-creating-a-generation-of-narcissists/. 